Northwestern University School of Law Northwestern University School of Law Scholarly Commons

Faculty Working Papers

2008

\title{
Litigation and the Optimal Combination of Vague and Precise Clauses in Contracts
}

Alvaro E. Bustos

\section{Repository Citation}

Bustos, Alvaro E., "Litigation and the Optimal Combination of Vague and Precise Clauses in Contracts" (2008). Faculty Working Papers. Paper 156.

http://scholarlycommons.law.northwestern.edu/facultyworkingpapers/156

This Working Paper is brought to you for free and open access by Northwestern University School of Law Scholarly Commons. It has been accepted for inclusion in Faculty Working Papers by an authorized administrator of Northwestern University School of Law Scholarly Commons. 


\title{
Litigation and the Optimal Combination of Vague and Precise Clauses in Contracts
}

\author{
Álvaro Bustos* \\ Northwestern University ${ }^{\dagger}$
}

October 2007

\begin{abstract}
In this paper we determine the optimal combination of precise and vague clauses written in contracts when the parties face writing and enforcement costs, the second ones in the form of litigation. We show that the parties may prefer to write vague instead of precise clauses not only because they are cheaper to write but also because they are cheaper to enforce. We extend Battigalli and Maggi (2002) to model the decision of a principal who chooses clauses to describe the actions that an agent has to perform. As both players observe nature imperfectly they may call for a court to determine whether the agent performed the right action. We show that the principal tends to sue the agent more frequently when a task is described with a precise instead of a vague clause. The reason is the following: with precise clauses, the frequency of litigation increases with the value of the task that is described because a smaller discrepancy in the beliefs of the players is enough to trigger a dispute, but with vague clauses, that frequency decreases with the value of the task because the probability that the agent performs the right action increases with the value of the task. The direct implication is that vague and not precise clauses (as it is predicted by Battigalli and Maggi) are used to describe the most important tasks of a contract.
\end{abstract}

Keywords: Optimal Combination of Clauses, Vague and Precise Clauses, Writing and Enforcement Costs, Litigation.

JEL classification: D86, K12, K41

\footnotetext{
*a-bustos@law.northwestern.edu

†This paper is a revised version of the second chapter of my PhD dissertation. I am grateful to Patrick Bolton and Bentley MacLeod for useful comments.
} 


\section{Introduction}

Legal scholars argue that the contracting parties should avoid writing clauses that are prohibitively expensive to enforce. However this prediction does not describe reality accurately as we often find commercial agreements including expressions like "the parties should act in good faith," "managers should make decisions in the best interest of shareholders" or "the agents are expected to make reasonable decisions." Why are the parties interested in including ambiguous terms in their contracts and when should they use them more intensively?

While precise clauses ${ }^{1}$ are terms that clearly specify the actions that the promisor should perform, vague clauses ${ }^{2}$ are terms that only demand best efforts from the promisor in the performed action. The literature suggests that the optimal combination of these clauses in contracts is determined by a trade-off between their writing and enforcement costs. Comparatively, precise clauses are more expensive to write because they provide detailed explanations of the actions for every possible scenario but would be cheaper to enforce because they are easier to interpret. ${ }^{3}$

We notice however that the papers that have studied contracts that face writing and enforcement costs (Dye (1985), Anderlini and Felli (1994 and 1999), Dewatripont and Maskin (1995), Bernheim and Whinston (1998), Krasa and Villamil (2000)) model the enforcement process in a much too simple way. ${ }^{4}$ These models fail to notice that the enforcement process is the resolution of a conflict between the promisor and the promisee in which a third party, usually a court, is called to make a decision. In that case focusing attention only in the cost of enforcement may be misleading because the process (litigation) may actually never take place. That could be the case if the promisor freely fulfills the demanded action or the court always decide in favor of one party. Among the few papers that take into account the role of litigation in the design of contracts, Triantis (2002) and Scott and Triantis (2006) develop a descriptive theory that identifies the combination of clauses that

\footnotetext{
${ }^{1}$ Also called complete or bright line rules.

${ }^{2}$ Also called incomplete rules or standards.

${ }^{3}$ Some times the literature presents the trade off between rules and standards in the following way: while rules mandate actions that are optimal at the moment of writing the contract, standards mandate actions that are optimal at the moment of enforcing the contract. Kraakman and Hansmann (2004) nicely describe this distinction in the context of corporate governance.

"By contrast, few jurisdictions rely on the rules (precise clauses) strategy as a principal device for regulating complex, intra-corporate relations, such as for example, self dealing transactions initiated by controlling shareholders. Such matters are presumably, too complex to regulate with a matrix of prohibitions and exemptions, which threaten to codify loopholes and create pointless rigidities. Rather than rule-based regulation, then intra-corporate topics such as insider self-dealing tend to be governed by open standards (vague clauses) that leave discretion for adjudicators to determine ex post whether violations have occurred."

For an extensive analysis see Kaplow (1992).

${ }^{4}$ They distinguish between verifiable and non-verifiable actions such that the first ones are relatively cheaper to enforce and the second ones can be substituted by second best verifiable actions. Consequently, optimal contracts should describe only a subset of the verifiable actions in order to save writing costs and replace the non-verifiable actions in order to save enforcing costs.
} 
optimally balances the distribution of evidentiary proxies (between the front- and back-end stage of a contract) that would be used, in the case of a legal dispute, to determine whether a contract was breached or not. ${ }^{5}$

In this paper we show that it is not always the case that the optimal selection of precise and vague clauses is determined by a trade-off between writing and enforcement costs. We show that the contracting parties may be interested in writing vague instead of contingent clauses because they are cheaper to write and, at the same time, cheaper to enforce (obviously that is not always the case otherwise the contract will only have vague clauses.) We model enforcement as a litigation process that the parties can generate in order to decide whether the contract was fulfilled or not. We show that in that case, precise clauses are more expensive to enforce because they tend to generate litigation more frequently than vague clauses.

Precise clauses are statements full of details that explain the conditions under which the promisor should perform a certain action, while vague clauses are simple statements that only demand best efforts in the performed action. Then, the more important (valuable for the promisee) is the action, the more likely is that a precise clause will generate a litigation because a smaller discrepancy between the parties about the interpretation of the clause will be enough to generate a dispute. Nevertheless the more valuable is the action the less likely is that a vague clause will generate a litigation because the promisor will make a higher effort in order to avoid the risk of having to compensate the promisee in a big amount of money.

We build on Battigalli and Maggi (2002) where a principal chooses among contingent (each state of nature induces a unique action), rigid (a set of states of nature induces a unique action) and discretionary clauses (a set of states of nature induces a set of actions) in order to describe the actions that an agent has to perform. The main prediction of the paper is that contingent clauses are used to describe the most important tasks, rigid clauses to describe tasks of intermediate importance and discretionary clauses for the least important ones.

As a matter of convention, contingent clauses correspond to what we and the literature calls precise clauses, hence we will use these terms interchangeably.

In our model we suppose that the parties can not only write contingent, rigid and discretionary clauses but also vague clauses. In addition, we assume that the parties observe the state of nature imperfectly. Then, while under precise clauses the agent is called to perform the action specified in the contract for the true state of nature, under vague clauses the agent is called to perform the action specified in the contract for what she believes is the true state of nature. Due to the imperfect observability the parties will have different beliefs whether the agent fulfilled the contract or not. If these differences are strong enough the parties will call for a court in order to resolve the dispute. We assume that the objective of the court is to enforce the contract and the remedy is

\footnotetext{
${ }^{5}$ The parties can choose to specify at the writing stage (front-end stage) how to determine whether the contract was fulfilled or they can leave this task to the court in the eventuality of a dispute (back-end stage).
} 
expectation damages.

The features of the equilibria when the parties face contingent and vague clauses are the following. Under a contingent clause, the agent always execute the correct action for her belief about the state of nature but the principal may sue her due to his belief that she observed the wrong state of nature. The higher the value of the task the higher the probability that the principal sues because the smaller is the conflict of beliefs required to trigger a trial. Under a vague clause, the agent may or may not execute the correct action for her belief about the state of nature and the principal may sue because of this. The court does not pay attention to the true state of nature but to the belief of the agent. The higher the value of the task the lower the probability that the principal sues because the higher is the probability that the agent executes the right action.

A first implication of the paper is that contracts use contingent clauses less frequently when the parties face writing and enforcement costs than when they only face writing costs. The reason is that neither discretionary nor rigid clauses generate trials as the agent never breaches the contract under them. A second implication is that contracts become even less intensive in contingent clauses when vague clauses are available because vague clauses are cheaper to write and cheaper to enforce if the value of the task is big enough. Directly from that and unlike in Battigalli and Maggi we conclude that the most important tasks of the optimal contract are described with vague and not contingent clauses. ${ }^{6}$

Unlike Scott and Triantis, our results are not sensitive to the relative ability of the players (principal, agent and court) to observe the correct state of nature. Contingent clauses generate more litigation than vague clauses only because they generate more conflicts leading the parties to trial. The relative abilities of the players to enforce the optimal contract do affect the frequency of litigation but that is true for vague and contingent clauses in the same way.

The rest of the paper is organized as follows. In Section 2 we describe the model: the basics of Battigalli and Maggi and the enforcement process. In Section 3 we determine the optimal combination of clauses when the parties face writing and enforcement costs but they cannot write vague clauses. In Section 4 we determine the optimal combination of precise and vague clauses. In Section 5 we conclude.

\section{The Model}

We start by describing the basics ${ }^{7}$ of Battigalli and Maggi (2002) and recalling the optimal contract when the parties only face writing costs. Later, we introduce the possibility that the parties face

\footnotetext{
${ }^{6}$ We find that the marginal benefit of a task is smaller when it is described with a vague clause than when it is described with a contingent clause, nevertheless this difference tends to disappear with the value of the task such that at certain point the difference in the frequency of trials makes the first type of clauses more desirable.

${ }^{7}$ For further details you may want to read the paper directly.
} 
enforcement costs in the form of a trial. We assume that the agents observe the state of nature imperfectly such that, depending on the value of the task that is described and the degree of the conflict of beliefs between the parties, they may decide to resolve their dispute (whether the agent performed the action demanded by the contract) in a court. In the next Section we determine the optimal combination of clauses in the presence of enforcement costs and compare it with the optimal combination of clauses when there are no enforcement costs.

\subsection{Basics of Battigalli-Maggi}

A principal offers an agent a contract. The contract is defined by $g=\wedge_{k=1}^{K}\left(\eta_{k} \longrightarrow \beta_{k}\right)$ and a transfer $t \in \mathbb{R}$ where $\eta_{k} \in \Lambda^{e}$ is a well-formed formula (later defined as a combination of sentences) about the environment and $\beta_{k} \in \Lambda^{a}$ is a well-formed formula about the behavior. $\Lambda^{e}$ is the set of all logical combinations of the primitive sentences describing an elementary event $\Pi^{e}=\left\{e_{1}, e_{2}, e_{3}, \ldots\right\}$ and $\Lambda^{a}$ is the set of all logical combinations of the primitive sentences describing an elementary action $\Pi^{a}=\left\{a_{1}, a_{2}, a_{3}, \ldots\right\}$. For example, in the case that the shareholders of a corporation (principal) want to specify the actions of the manager/CEO (agent) when she faces a takeover offer the event $e_{k}$ can be "offer is for more than $20 \%$ of the outstanding shares" or "offered price per share is above $200 \%$ of its market value" and the action $a_{k}$ can be "accept the takeover" or "call for a shareholders meeting". As logical connectors BM identify $\neg$ ("not"), $\wedge$ ("and"), $\vee($ "or"), $\longrightarrow$ ("if...then") the parentheses and the logical constant $T$ ("tautology"). Then, contract $g$ is an obligation for the principal to transfer an amount $t$ to the agent and a set of clauses in which the agent is supposed to perform $a_{k}$ if $e_{k}$ takes place. Notice that the transfer is paid regardless the action is performed or not.

From this characterization BM are able to identify a complete contract as a set of clauses in which each state induces the agent to perform a particular action. They call these clauses: contingent. On the other side, an incomplete contract may contain clauses of two types. Clauses that incompletely characterize the event space, which they call rigid (for example, independent of the characteristics of the offer always accept it) and clauses that incompletely characterize the action space, which they call discretionary (for example, if the offer is for more than $20 \%$ of the outstanding shares then the manager must make a decision).

The cost of writing contract $g$ is $C(g)=c n^{g}$ in which $c$ is a constant cost and $n^{g}$ is the number of primitive sentences (regardless they are $e_{k}$ or $a_{k}$ ). Implicit in this definition, there are no writing costs associated to the logical connectives.

After the principal offers the contract, the state of nature is realized and the agent chooses her behavior. By assumption only the principal pays the writing costs and renegotiation is ruled out.

Consequently, the principal's payoff is $\pi(s, b)-t-C(g)$ while the agent's payoff is $t-\delta \pi(s, b)$ 
in which

$$
\pi(s, b)=\sum_{n=1}^{N} \pi_{n}\left[s\left(e_{n}\right) b\left(a_{n}\right)+\left(1-s\left(e_{n}\right)\right)\left(1-b\left(a_{n}\right)\right)\right]
$$

In this expression, $\pi_{n} \in\left[\pi_{\min }, \pi_{\max }\right]$ and positive is the principal's incremental benefit from matching $e_{n}$ with $a_{n}$ or $\neg e_{n}$ with $\neg a_{n}$. By its side $s\left(e_{n}\right)$ is a dummy variable that takes value 1 if the state of nature $e_{n}$ takes place and 0 otherwise and $b\left(a_{n}\right)$ is a dummy variable that takes value 1 if the agent executes action $a_{n}$ and 0 otherwise. As BM explains it, that is a very simple payoff structure in which the principal obtains (maximum) benefit 1 if and only if the agent performs the optimal action for each state of nature: action $a_{n}$ for state of nature $e_{n}$ and action $\neg a_{n}$ for state of nature $\neg e_{n}$. The parameter $\delta \in[0,1]$ captures the strength of the conflict of interests between principal and agent. ${ }^{8}$

The principal and agent's prior beliefs about the exogenous states are given by a common probability measure $\mu \in \Delta(s)$ such that the states of nature $e_{n}, n=1, \ldots, N$, are i.i.d. and take place with probability $p>1 / 2 .{ }^{9}$

The optimal contract is the one that maximizes the expected joint surplus net of writing costs.

$$
\max _{g \in F}\left\{\sum_{s \in S} \mu(s)\left[A \pi\left(s, B R^{g}(s)\right)-C(g)\right]\right\}
$$

in which $A=1-\delta$ captures the potential gains due to contracting, $F$ is the set of feasible contracts, $S=\{0,1\}^{\Pi^{e}}$ is the set of all possible states and $B R^{g}(s)=\underset{b}{\arg \min }(\delta \pi(s, b))$ is the best response of the agent at state $s$ given contract $g$.

\subsection{Optimal Contract}

According to their motivation, BM determine the clauses that the parties should include in the contract that minimizes writing costs.

\begin{tabular}{|c|c|c|}
\hline \multicolumn{2}{|c|}{ Table 1. Candidate Clauses for Task $n$} \\
\hline Clause & Symbology & Pay-off \\
\hline Contingent (C) & $\left(e_{n} \longrightarrow a_{n}\right) \wedge\left(\neg e_{n} \longrightarrow \neg a_{n}\right)$ & $A \pi_{n}-2 c$ \\
\hline Rigid (R) & $T \longrightarrow a_{n}$ & $p A \pi_{n}-c$ \\
\hline Discretionary (D) & $T \longrightarrow T$ & 0 \\
\hline
\end{tabular}

Table 1 tells us that rigid rules (for all states do $a_{n}$ ) are preferred to discretionary ones (for any state do anything) if and only if $\pi_{n}>c / p A$ while contingent rules (for state $e_{n}$ do $a_{n}$ and for any

\footnotetext{
${ }^{8}$ The larger $\delta$ the stronger the conflicts of interest.

${ }^{9}$ Explain intuition.
} 
other state don't do $\left.a_{n}\right)$ are preferred to rigid ones if and only if $\pi_{n}>c /(1-p) A$. That means that contingent rules $(\mathrm{C})$ are used to describe the most important tasks, rigid rules $(\mathrm{R})$ to describe tasks of intermediate importance and discretionary rules (D) for the least important ones. Figure 1 shows that decomposition graphically

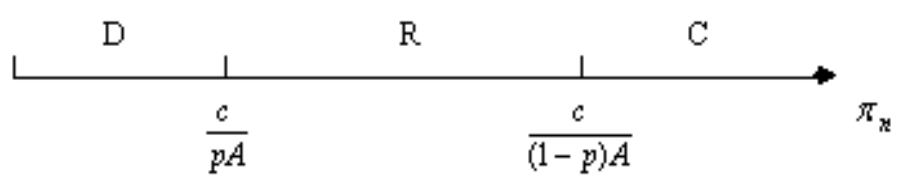

Figure 1

Optimal combination of clauses when writing is costly but enforce ment is costless.

The intuition is that the higher is the value of a task the more relevant is to assure that the agent performs the right action. In addition, their model tells us that the more likely is a state (the higher the value of $p$ ) the more intensive becomes the contract in the use of rigid clauses (displacing discretionary and contingent clauses). The reason is that the more likely is the realization of the state of nature for which $a_{n}$ is the right action the higher is the probability that the contract generates the maximum surplus $A$ at cost $c$ and not $2 c$. Finally, the higher are the writing costs relative to the potential gross surplus $(c / A)$ the more intensive becomes the contract in "incomplete clauses" (discretionary and rigid displace contingent). Obviously the reason is that the expected benefits of describing the action that should be executed when a state of nature takes place increases with the gross surplus but decreases with the writing costs.

\subsection{Enforcement Process}

The framework of BM assumes that the parties have the same information and all the actions are observable and verifiable. Consequently, at no point there is necessity to call a "third party" to control whether the agent fulfilled the action commanded by the contract. Reality rarely satisfies all these assumptions. Instead we should expect that the parties will have different beliefs of what is the true state of nature (for example what is the fair value of a corporation) or the level of complexity of some of the actions will make them non verifiable (for example whether a manager made enough effort to attract all potential buyers of the corporation). Here, we explicitly model the first consideration and assume that the parties (agent (A) and principal $(\mathrm{P})$ ) have different beliefs about the true state of nature. Each of them receive a signal $S_{A(P)} \in\{1,0\}$ such that if $S_{A(P)}=1$ then $A(P)$ believes that the true state of nature is $e_{n}$ while if $S_{A(P)}=0$ then $A(P)$ believes that the true state of nature is $\neg e_{n}$. The agent observes the true state of nature only with probability 
$P\left(S_{A}=1 \mid e_{n}\right)=P\left(S_{A}=0 \mid \neg e_{n}\right)=1-\varepsilon_{A}$ while the principal does it only with probability $P\left(S_{P}=1 \mid e_{n}\right)=P\left(S_{P}=0 \mid \neg e_{n}\right)=1-\varepsilon_{P} .^{10}$

We reinterpret the framework of BM regarding the cost faced by the agent and consider that once the signal is received she has to decide whether to make a high or low effort. In the first case she executes the action demanded by the contract (for example in the case of a contingent clause $b\left(a_{n}\right)=1$ when $s\left(e_{n}\right)=1$ and $b\left(\neg a_{n}\right)=1$ when $\left.s\left(\neg e_{n}\right)=1\right)$ and incurs in a cost ${ }^{11} \delta \pi_{n}$ while in the second case she doesn't execute the action demanded by the contract and faces no cost.

By his side, the principal pays the agent the transfer $t$ if and only if he believes the right action is executed. If he believes the wrong action has been executed it may decide to sue the agent and demand a legal remedy (later we detail when this takes place.)

In the case of a legal dispute the parties share the litigation expenses $\kappa$ in equal parts and a court is called to make a decision. The objective of the court is to determine whether the contract has been fulfilled by the agent or not. ${ }^{12}$ In order to do that the court observes the action executed by the agent and observes its own signal $S_{C} \in\{1,0\}$ which reveals the true state of nature with probability $1-\varepsilon_{C}$.

Consequent with expectation damages, the damages for the breach of the contract compensate the promisee (principal) for the injury caused by the non-performing promisor (agent). ${ }^{13}$ In practical terms, under a favorable decision (the court believes that the agent executed the right action) the agent gets $t$ while under a non-favorable decision (the court believes that the agent executed the wrong action) the agent pays the principal $\pi_{n}$ (compensates him for the utilities he should have obtained.)

The former description leads to the following timing of actions (which differs from BM)

Timing of actions 1 . The principal determines the value of the transfer $t 2$. The agent receives her signal and decides what action to execute. 3. The principal receives his signal, observes the agent's action and then decides to pay $t$ or sue the agent for breach of contract. 4. The court observes its own signal and decides in favor of one of the parties. 5. Payoffs are realized.

\footnotetext{
${ }^{10}$ Clearly the two signals are correlated. For example

$$
\begin{gathered}
P\left(S_{A}=1 \mid S_{P}=1\right)=P\left(S_{A}=1 \mid e\right) P\left(e \mid S_{P}=1\right)+P\left(S_{A}=1 \mid \neg e\right) P\left(\neg e \mid S_{P}=1\right) \\
=\frac{\left(1-\varepsilon_{A}\right)\left(1-\varepsilon_{P}\right) p+\varepsilon_{A} \varepsilon_{P}(1-p)}{\left(1-\varepsilon_{P}\right) p+\varepsilon_{P}(1-p)}>\left(1-\varepsilon_{A}\right) p+\varepsilon_{A}(1-p)=P\left(S_{A}=1\right)
\end{gathered}
$$

${ }^{11}$ The expresion increases with the value of the task. That makes the formulation slightly more complicated but allows us to compare the results with BM.

${ }^{12}$ Unlike in Bustos [2005] in which the court enforces the rule that maximizes the intertemporal utility of the economic agents, here the court enforces the rule that the parties wanted before they wrote the contract.

${ }^{13}$ Under expectation damages the victim is indifferent between performance and breach (for a detailed explanation see Cooter and Ulen (2003)).
} 


\section{Optimal Clauses in the Presence of Enforcement Costs}

In this section we determine the optimal combination of contingent, rigid and discretionary clauses when the parties not only face writing costs but also enforcement costs (litigation) and then compare it with the optimal combination of clauses when the parties only face writing costs. We show that still is true that the most important tasks are described with contingent clauses. However, contingent clauses are used less frequently. The reason is that, unlike discretionary and rigid clauses, they can generate (costly) litigation. Under a contingent clause the principal never claims that the agent has intentionally executed the wrong action because he knows that she always make high effort but he may claim that the agent executed the wrong action due to an erroneous belief about the state of nature.

A central result of this Section is that the probability that the principal sues the agent increases with the value of the task that is described by the clause. The reason is that, the higher is this value the smaller is the threshold in the intensity of the conflict of beliefs between the parties that will trigger a trial.

\subsection{Assumptions}

First we introduce two restrictions in the parameters that allow us to simplify the mathematical analysis. Said that, we believe that the results apply to more general conditions.

Assumption 1 (Misperceptions are small): $\varepsilon_{A}, \varepsilon_{B}, \varepsilon_{C}<1 / 2$.

Assumption 2 (Existence of pure strategies equilibrium):

$$
\delta \leq \frac{\left(1-\varepsilon_{A}\right) \varepsilon_{A}\left(1-2 \varepsilon_{C}\right)(2 p-1)\left(\left(1-\varepsilon_{P}\right)^{2}+\left(\varepsilon_{P}\right)^{2}\right)}{\left[\left(1-\varepsilon_{A}\right) p+\varepsilon_{A}(1-p)\right]\left[p\left(\varepsilon_{P}-\varepsilon_{A}\right)-\varepsilon_{P} \varepsilon_{A}+\max \left(\varepsilon_{P}, \varepsilon_{A}\right)\right]} \frac{\pi_{\min }}{\pi_{\max }}
$$

\subsection{Strategies of the Players}

We use backward induction to characterize the game played by the agent, the principal and the court before the payoffs are realized. Although there is a mixed and a pure strategies equilibrium we only characterize the last one because we get a clearer intuition of the results.

\section{Court assigns responsibilities}

For each type of clause the court decides in favor of the agent when

Contingent Clauses: the agent executed $a_{n}$ and $S_{C}=1$ or executed $\neg a_{n}$ and $S_{C}=0$.

Rigid Clauses: the agent executed $a_{n}$ regardless $S_{C}=1$ or $S_{C}=0$.

Discretionary Clauses: the agent executed $a_{n}$ or $\neg a_{n}$ regardless $S_{C}=1$ or $S_{C}=0$ 
If we denote by $\sigma(\Omega)$ the a-priori probability that the court decides in favor of the agent, where $\Omega$ is the available information of the player who is making the estimation then: under a contingent clause this probability is $\left(1-\varepsilon_{C}\right) P\left(e_{n} \mid \Omega\right)+\varepsilon_{C} P\left(\neg e_{n} \mid \Omega\right)$ when the agent executes $a_{n}$ (court observes that state of nature is $\left.e_{n}\right)$ and $\varepsilon_{C} P\left(e_{n} \mid \Omega\right)+\left(1-\varepsilon_{C}\right) P\left(\neg e_{n} \mid \Omega\right)$ when the agent executes $\neg a_{n}$ (court observes that state of nature is $\neg e_{n}$ ). Under a rigid clause this probability is 1 if the agent executes $a_{n}$ and 0 if the agent executes $\neg a_{n}$. Under a discretionary clause this probability is 1 as the court always decide in favor of the agent.

\section{Principal decides to pay $t$ or sue}

We analyze the decision of the principal for each of the clauses.

1. Under a contingent clause, the principal sues the agent if and only if

$\underbrace{\underbrace{\sigma\left(\Omega_{P}\right)\left(p\left(\Omega_{P}\right) \pi_{n}-t\right)}_{\text {Decision favors agent }}+\underbrace{\left(1-\sigma\left(\Omega_{P}\right)\right)\left(\pi_{n}+p\left(\Omega_{P}\right) \pi_{n}\right)}_{\text {Decision favors principal }}}_{\text {Principal sues }}-\frac{\kappa}{2}>\underbrace{\text { Agent executes right action }}_{\text {Principal doesn't sue }} \underbrace{p\left(\Omega_{P}\right) \pi_{n}}_{\text {Expected Transfer }}$

where $p\left(\Omega_{P}\right)$ is the probability that the agent made the decision demanded by the contract (before the principal decided to sue) and $\sigma\left(\Omega_{P}\right)$ is the probability that the court decides in favor of the agent in both cases, given the information owned by the principal $\Omega_{P}$.

The principal sues the agent only if the expected benefits of letting the court decide whether the agent performed the action demanded by the contract are higher than the expected benefits generated by the action of the agent $p\left(\Omega_{P}\right) \pi_{n}$ minus the compensation that the principal is willing to pay $\sigma\left(\Omega_{P}\right) t$. This last expression requires more explanation.

The principal would prefer not to pay the transfer $t$ to the agent at all, nevertheless, if he does that and it is true that $\sigma\left(\Omega_{A}\right) t-\kappa / 2>0$ the agent will sue the principal for breach of contract. By its side the principal doesn't want this trial as that would cost him $\sigma\left(\Omega_{P}\right) t+\kappa / 2$ and would generate no benefits. Instead the principal is willing to offer a maximum of $\sigma\left(\Omega_{P}\right) t$ to the agent to settle the dispute. In order to keep the analysis simple, we assume that the agent has all the bargaining power when both players observe the same signal $\left(\sigma\left(\Omega_{A}\right) t<\sigma\left(\Omega_{P}\right) t\right)$ because in this case the evidence favors her but the principal has all the bargaining power when both players observe different signals $\left(\sigma\left(\Omega_{A}\right) t>\sigma\left(\Omega_{P}\right) t\right)$ because in this case the evidence is divided. Consequently as the agent always extract $\sigma\left(\Omega_{P}\right) t$ in the eventuality of a bargaining process the principal freely offers that amount when he decides not to sue.

The principal initiates legal actions if and only if the value of the task is bigger than the litigation costs divided by the probability that the court decides in his favor

$$
\bar{\pi}_{n}=\frac{\kappa / 2}{1-\sigma\left(\Omega_{P}\right)}
$$


At this point we notice that due to the revelation principle the principal offers the agent the transfer that induces her to make high effort with certainty. In that case the action of the agent truthfully reveals her signal. Given that, we identify four possible values of $\sigma\left(\Omega_{P}\right)$ and $\bar{\pi}_{n}$ which are summarized in the following table

\begin{tabular}{|c|c|c|}
\hline$\Omega_{P}$ & $\sigma\left(\Omega_{P}\right)$ & $p_{T}\left(\Omega_{P}\right)$ \\
\hline$S_{A}=S_{P}=1$ & $\frac{\left(1-\varepsilon_{A}\right)\left(1-\varepsilon_{P}\right) p\left(1-\varepsilon_{C}\right)+\varepsilon_{A} \varepsilon_{P}(1-p) \varepsilon_{C}}{\left(1-\varepsilon_{A}\right)\left(1-\varepsilon_{P}\right) p+\varepsilon_{A} \varepsilon_{P}(1-p)}$ & $\begin{array}{l}1 \text { if } \pi_{n} \geq \bar{\pi}^{11} \\
0 \text { if } \pi_{n}<\bar{\pi}^{11}\end{array}$ \\
\hline$S_{A}=1 ; S_{P}=0$ & $\frac{\left(1-\varepsilon_{A}\right) \varepsilon_{P} p\left(1-\varepsilon_{C}\right)+\varepsilon_{A}\left(1-\varepsilon_{P}\right)(1-p) \varepsilon_{C}}{\left(1-\varepsilon_{A}\right) \varepsilon_{P} p+\varepsilon_{A}\left(1-\varepsilon_{P}\right)(1-p)}$ & $\begin{array}{l}1 \text { if } \pi_{n} \geq \bar{\pi}^{10} \\
0 \text { if } \pi_{n}<\bar{\pi}^{10}\end{array}$ \\
\hline$S_{A}=0 ; S_{P}=1$ & $\frac{\left(1-\varepsilon_{A}\right) \varepsilon_{P}(1-p)\left(1-\varepsilon_{C}\right)+\varepsilon_{A}\left(1-\varepsilon_{P}\right) p \varepsilon_{C}}{\left(1-\varepsilon_{A}\right) \varepsilon_{P}(1-p)+\varepsilon_{A}\left(1-\varepsilon_{P}\right) p}$ & $\begin{array}{l}1 \text { if } \pi_{n} \geq \bar{\pi}^{01} \\
0 \text { if } \pi_{n}<\bar{\pi}^{01}\end{array}$ \\
\hline$S_{A}=S_{P}=0$ & $\frac{\left(1-\varepsilon_{A}\right)\left(1-\varepsilon_{P}\right)(1-p)\left(1-\varepsilon_{C}\right)+\varepsilon_{A} \varepsilon_{P} p \varepsilon_{C}}{\left(1-\varepsilon_{A}\right)\left(1-\varepsilon_{P}\right)(1-p)+\varepsilon_{A} \varepsilon_{P} p}$ & $\begin{array}{l}1 \text { if } \pi_{n} \geq \bar{\pi}^{00} \\
0 \text { if } \pi_{n}<\bar{\pi}^{00}\end{array}$ \\
\hline
\end{tabular}

A central result of the paper is that the probability that the principal sues the agent increases with the value of the task $\pi_{n}$. The reason is that the benefit of a trial-relative to the benefit of not having trial - is the value of the task times the probability that the court decides in favor of the principal which is a constant. Alternativelly the set of combinations of signals observed by the players that generate a trial increases with the value of $\pi_{n}$. Even more, it is easy to show ${ }^{14}$ that $\bar{\pi}^{11}>\bar{\pi}^{00}>\bar{\pi}^{10}>\bar{\pi}^{01}$ (the first superindex refers to the signal observed by the agent and teh second superindex to the signal observed by the principal) which means that trials take place more frequently when the principal and the agent receive different signals as the conflict of beliefs is stronger than in the case in which they receive the same signals. ${ }^{15}$ We summarize the former considerations in the following lemma

Lemma 1 Under contingent clauses the frequency of trials increases with $\pi_{n}$

Proof. Directly from table 2, the a-priori probability that a trial takes place is

$$
p_{T}\left(\Omega_{P}\right)=\left\{\begin{array}{c}
0 \text { if } \pi_{n}<\bar{\pi}^{01} \\
P\left(S_{A}=0 ; S_{P}=1\right) \text { if } \pi_{n} \in\left[\bar{\pi}^{01}, \bar{\pi}^{10}\right] \\
P\left(S_{A}=0 ; S_{P}=1\right)+P\left(S_{A}=1 ; S_{P}=0\right) \text { if } \pi_{n} \in\left[\bar{\pi}^{10}, \bar{\pi}^{00}\right] \\
P\left(S_{A}=0 ; S_{P}=1\right)+P\left(S_{A}=1 ; S_{P}=0\right)+P\left(S_{A}=S_{P}=0\right) \text { if } \pi_{n} \in\left[\bar{\pi}^{00}, \bar{\pi}^{11}\right] \\
1 \text { if } \pi_{n}>\bar{\pi}^{11}
\end{array}\right.
$$

\footnotetext{
${ }^{14}$ Here we use assumption 1.

${ }^{15}$ In addition trials take place more frequently when the principal observes that the true state of nature is $\neg e$ because this state of nature, unconditionally, takes place less frequently than $e$ (recall that $p>1 / 2$ ).
} 
which establishes the result

The lemma tells us what is the effect of the ability of each player $\left(\varepsilon_{A}, \varepsilon_{P}\right.$ and $\left.\varepsilon_{C}\right)$ over the decision of the court. The less able is the agent, the more frequently the court decides in favor of the principal $\left(\sigma\left(\Omega_{P}\right)\right.$ decreases with $\left.\varepsilon_{A}\right)$. The less able is the principal the more frequently the court decides in favor of the agent when the signals are different but the less frequently when the signals are the same. The reason is that in the first case the court becomes less certain that the agent observed the right signal while in the second one it becomes more certain. Finally, we cannot conclude whether an increment in the ability of the court increases or decreases the probability of a decision in favor of the agent because the mistakes of the court can go in both directions. The aggregate effect will depend on the relative capacities of the parties in dispute. Lemma A.1 of the appendix formally proves these results.

You may notice that we have not mentioned whether the agent (who doesn't perform the right action and is sued) prefers to litigate, pay the damages or settle the dispute. As we show in the appendix, thanks to assumption 2 which says that $\delta$ is not very big and the fact that we have ruled out renegotiation, she always prefer litigation. The reason depends on whether the parties observe the same or different signals. In the first case the value in dispute $\pi_{n}+t$ is big enough to make litigation preferable. In the second case the differences in beliefs about the state of nature are strong enough to make litigation preferable.

2. Under a rigid clause the principal never sues because the court always decide in favor of the agent. As the agent always execute $a_{n}$ (regardless of what signal did she observe) there is no space for mistakes. Then, it is never profitable for the principal to sue.

3. Under a discretionary clause the principal never sues for obvious reasons.

\section{Agent decides effort}

When the agent observes $S_{A}=1$ she decides to make high effort if and only if

$$
\begin{gathered}
p_{T}\left(\Omega_{A}^{1}\right)\left[\sigma\left(\Omega_{A}^{1}\right) t-\left(1-\sigma\left(\Omega_{A}^{1}\right)\right) \pi_{n}-\frac{\kappa}{2}\right]-\left(1-p_{T}\left(\Omega_{A}^{1}\right)\right)\left[\sigma\left(\Omega_{A}^{1}\right) t\right]-\delta \pi_{n}> \\
p_{T}\left(\bar{\Omega}_{A}^{1}\right)\left[\sigma\left(\bar{\Omega}_{A}^{1}\right) t-\left(1-\sigma\left(\bar{\Omega}_{A}^{1}\right)\right) \pi_{n}-\frac{\kappa}{2}\right]-\left(1-p_{T}\left(\bar{\Omega}_{A}^{1}\right)\right)\left[\sigma\left(\bar{\Omega}_{A}^{1}\right) t\right]
\end{gathered}
$$

where $\Omega_{A}^{1}$ is the information set in which the agent observes signal $S_{A}=1$ and executes $a_{n}$ while $\bar{\Omega}_{A}^{1}$ is the information set in which the agent observes signal $S_{A}=1$ and executes $\neg a_{n}$. The relation tells us that the agent makes high effort only when the expected savings for facing trials less frequently are bigger than the cost of making a higher effort. Analogously, when the agent observes $S_{A}=0$ 
she decides to make high effort if and only if

$$
\begin{gathered}
p_{T}\left(\Omega_{A}^{0}\right)\left[\sigma\left(\Omega_{A}^{0}\right) t-\left(1-\sigma\left(\Omega_{A}^{0}\right)\right) \pi_{n}-\frac{\kappa}{2}\right]-\left(1-p_{T}\left(\Omega_{A}^{0}\right)\right)\left[\sigma\left(\Omega_{A}^{0}\right) t\right]-\delta \pi_{n}> \\
p_{T}\left(\bar{\Omega}_{A}^{0}\right)\left[\sigma\left(\bar{\Omega}_{A}^{0}\right) t-\left(1-\sigma\left(\bar{\Omega}_{A}^{0}\right)\right) \pi_{n}-\frac{\kappa}{2}\right]-\left(1-p_{T}\left(\bar{\Omega}_{A}^{0}\right)\right)\left[\sigma\left(\bar{\Omega}_{A}^{0}\right) t\right]
\end{gathered}
$$

where this time the information sets $\Omega_{A}^{0}$ and $\bar{\Omega}_{A}^{0}$ refer to the cases in which the agent observes $S_{A}=0$.

\section{Principal determines the value of the transfer}

Due to the revelation principle the principal always prefer the agent to make high effort. The principal imposes the minimum transfer that achieves that result. In the appendix we show that (3) is always satisfied when $t>\frac{\delta \bar{\pi}^{01}}{\sigma\left(\Omega_{A}^{1}\right)-\sigma\left(\bar{\Omega}_{A}^{1}\right)}$ and (4) is always satisfied when $t>\frac{\delta \bar{\pi}^{01}}{\sigma\left(\bar{\Omega}_{A}^{0}\right)-\sigma\left(\Omega_{A}^{0}\right)}$. The reason is that the probability that the agent makes high effort is minimal when trials never take place $\left(p_{T}\left(\Omega_{A}^{1}\right)=p_{T}\left(\bar{\Omega}_{A}^{1}\right)=0\right)$. In that case it may seem that the agent would always want to make low effort. Nevertheless the fact that the principal would pay her no transfer convinces her to make the high effort. Consequently, the principal chooses $t^{*}=\max \left\{\frac{\delta \bar{\pi}^{01}}{\sigma\left(\Omega_{A}^{1}\right)-\sigma\left(\bar{\Omega}_{A}^{1}\right)}, \frac{\delta \bar{\pi}^{01}}{\sigma\left(\Omega_{A}^{0}\right)-\sigma\left(\bar{\Omega}_{A}^{0}\right)}\right\}$ and assures that the agent always make high effort. Notice that assumption 2 tells us that $\pi_{n}-t^{*}>0$ for all $\pi_{n} \in\left[\pi_{\min }, \pi_{\max }\right]$.

\subsection{Optimal Contract (without vague clauses)}

As in $\mathrm{BM}$, we are interested in finding the combination of clauses that maximizes the aggregate utility of the agent and the principal. That is, we want to maximize

$$
\sum_{i=0,1} \sum_{j=0,1}\left\{\begin{array}{c}
p\left(1-\varepsilon_{A}\right)^{i}\left(\varepsilon_{A}\right)^{(1-i)}\left(1-\varepsilon_{P}\right)^{j}\left(\varepsilon_{P}\right)^{(1-j)}\left[p_{T}\left(\Omega_{P}\right) \widetilde{E}_{S}^{i j}+\left(1-p_{T}\left(\Omega_{P}\right)\right) \bar{E}_{S}^{i j}\right] \\
+(1-p)\left(1-\varepsilon_{A}\right)^{i}\left(\varepsilon_{A}\right)^{(1-i)}\left(1-\varepsilon_{P}\right)^{j}\left(\varepsilon_{P}\right)^{(1-j)}\left[p_{T}\left(\Omega_{P}\right) \widetilde{E}_{S}^{i j}+\left(1-p_{T}\left(\Omega_{P}\right)\right) \bar{E}_{S}^{i j}\right.
\end{array}\right\}
$$

where $\widetilde{E}_{S}^{i j}$ is the aggregate utility when the agent observes signal $i$, the principal observes signal $j$ and there is litigation and $\bar{E}_{S}^{i j}$ is the same aggregate utility but this time when there is no litigation. Expression (5) takes into account all the possible combinations of states of nature and signals observed by the players. Notice that the probability of a trial is the one with which the principal sues the agent. The next table summarizes the payoffs for the different clauses as a function of the value of the task that is described in the contract (in the appendix we provide a detailed calculation of these values). 


\begin{tabular}{|c|c|c|}
\hline \multicolumn{2}{|c|}{ Table 3. Candidate Clauses for Task $n$ (with enforcement costs) } \\
\hline Clause & Symbology & Pay-off \\
\hline Contingent (C) & $\left(e_{n} \longrightarrow a_{n}\right) \wedge\left(\neg e_{n} \longrightarrow \neg a_{n}\right)$ & $\left(1-\varepsilon_{A}\right) A \pi_{n}-2 c-\left\{\begin{array}{c}\kappa \text { if } \pi_{n}>\bar{\pi}^{11} \\
\alpha_{1} \kappa \text { if } \pi_{n} \in\left[\bar{\pi}^{00}, \bar{\pi}^{11}\right] \\
\alpha_{2} \kappa \text { if } \pi_{n} \in\left[\bar{\pi}^{10}, \bar{\pi}^{00}\right] \\
\alpha_{3} \kappa \text { if } \pi_{n} \in\left[\bar{\pi}^{01}, \bar{\pi}^{10}\right] \\
0 \text { if } \pi_{n}<\bar{\pi}^{01}\end{array}\right.$ \\
\hline Rigid (R) & $T \longrightarrow a_{n}$ & $p A \pi_{n}-c$ \\
0 \\
\hline Discretionary (D)
\end{tabular}

The benefit of a contingent clause $\left(1-\varepsilon_{A}\right) A \pi_{n}$ only depends on the ability of the agent to observe the correct state of nature. The abilities of the principal $\left(\varepsilon_{P}\right)$ and the court $\left(\varepsilon_{C}\right)$ are not relevant from a social point of view because they don't affect the frequency with which the agent executes the right action (recall that the agent always make high effort).

The cost of a contingent clause is of the form $2 c+\alpha \kappa$. The first part refers to the writing process while the second one to the enforcement process. More specifically, the parameter $\alpha$ captures the frequency with which the principal sues the agent due to a supposed breach of the contract. This frequency increases with the incapacity of the agent to observe the true state of nature as well as with the incapacity of the same principal to observe the true state. Unlike the first point the second one is not obvious because the principal knows that the court may decide less frequently in his favor when he is less reliable however the fact that he thinks that the agent is more often mistaken dominates his final decision. Once again the ability of the court is irrelevant from the social point of view because its judicial decision imposes only a transfer of value between the agent and the principal. However the ability of the court, as well as the ability of the parties, do affect the incentives faced by the principal to initiate a trial and that is captured by the dependence of the limits $\bar{\pi}_{n}$ with respect to $\varepsilon_{C} \cdot{ }^{16}$

On a different side, notice that although the marginal benefit of a contingent clause doesn't change, the marginal cost of litigation increases (at intervals) with the value of the task. The reason is that the principal has higher incentives to be sure that the agent will execute the right action.

A direct implication of comparing tables 1 and 3 is that the pay-off of contingent clauses when the parties face enforcement costs is smaller than the pay-off of the same clauses when they don't

\footnotetext{
${ }^{16}$ From a social point of view, more litigation is not desirable because it only constitutes a transfer between the players but from the point of view of the principal it is a way to extract a higher portion of the incremental benefits associated to task $n$.
} 
face these costs. There are two reasons for that. First, the agent executes the wrong action when she observes the wrong state of nature and second, litigation is costly. ${ }^{17}$ The pay-off of a rigid or discretionary clause does not change because neither of them induces the principal to sue the agent. As a result, from a social point of view, contracts should be less intensive in contingent clauses than what the analysis of BM suggests.

However it is still true that the most important tasks are described with contingent clauses because it is still true that they achieve a higher marginal benefit than the "incomplete" clauses. ${ }^{18}$ The next proposition summarizes the former considerations.

Proposition 2 Contracts in which the parties face writing and enforcement costs use contingent clauses less frequently than contracts in which the parties don't face enforcement costs. However unless the agent often misinterprets the true state of nature $\left(\varepsilon_{A}<1-p\right)$ it is still true that contingent clauses are used to describe the most important tasks of the contract.

Proof. The pay-off of a contingent clause when there are no enforcement costs is $A \pi_{n}-2 c$ (table 1). The pay-off of a contingent clause when there are enforcement costs is of the general form $\left(1-\varepsilon_{A}\right) A \pi_{n}-2 c-\alpha \kappa$ (table 3$)$. Hence, there are values of $\pi_{n}$ for which contingent clauses are preferred to rigid ones when there are enforcement costs but are not preferred when there are only writing costs. In addition, for all values of $\pi_{n}$ for which contingent clauses are preferred to rigid ones when there are enforcement costs it is true that contingent clauses are preferred to rigid ones when there are not enforcement costs. Consequently, the set of tasks described with contingent clauses is smaller when there are enforcement costs than when there are only writing costs.

In order to see that contingent clauses are used to describe the most important tasks we notice the following. The highest and the lowest payoffs of a contingent clause are $\left(1-\varepsilon_{A}\right) A \pi_{n}-2 c$ and $\left(1-\varepsilon_{A}\right) A \pi_{n}-2 c-\kappa$ respectively. The pay-off of a rigid clause is $p A \pi_{n}-c$. Then conditional on $\varepsilon_{A}<1-p$ we identify two cases of optimal combination of clauses in contracts.

Case 1: there exists a value $\pi^{*} \in\left[\frac{c}{\left(1-p-\varepsilon_{A}\right) A}, \frac{c+\kappa}{\left(1-p-\varepsilon_{A}\right) A}\right]$ such that all tasks with value $\pi_{n} \in$ $\left[\pi^{*}, c / p A\right]$ are described with rigid clauses and all tasks with value $\pi_{n} \geq \pi^{*}$ are described with

\footnotetext{
${ }^{17} \mathrm{It}$ is direct to notice that the pay-off of a contingent clause is the same in tables 1 and $3 \mathrm{when} \varepsilon_{A}=\kappa=0$.

${ }^{18}$ To see that point it is enough to make $\pi_{n}$ big enough to compensate for the additional costs of facing an enforcement process.
} 
contingent clauses as it is shown in figure 2 .

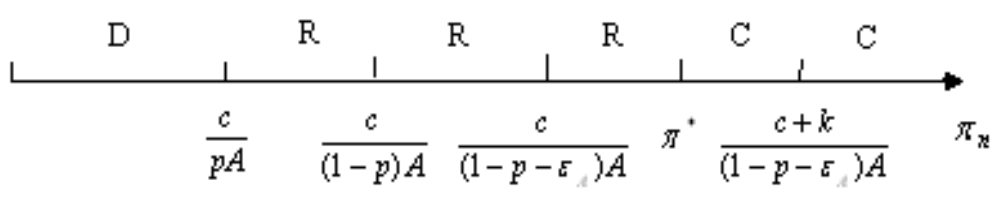

Figure 2

Optimal combination of clauses with writing and enforcement costs: Case 1

The pay-off of a contingent clause is higher than the pay-off of a rigid clause when $\pi_{n}>$ $\frac{c+\kappa}{\left(1-p-\varepsilon_{A}\right) A}$ but the pay-off of a rigid clause is higher than the pay-off of a contingent clause when $\pi_{n}<\frac{c}{\left(1-p-\varepsilon_{A}\right) A}$. In addition, as the pay-off of contingent clauses is step-wise we must have $\pi^{*} \in\left\{\frac{c+\alpha_{i} \kappa}{\left(1-p-\varepsilon_{A}\right) A}\right\}_{1,2,3}$ which belongs to the interval $\left[\frac{c}{\left(1-p-\varepsilon_{A}\right) A}, \frac{c+\kappa}{\left(1-p-\varepsilon_{A}\right) A}\right]$. Nevertheless, in order to assure the shape of the solution we need some extra conditions, it must be true that $\frac{c+\alpha_{1} \kappa}{\left(1-p-\varepsilon_{A}\right) A} \notin\left[\bar{\pi}^{00}, \bar{\pi}^{11}\right], \frac{c+\alpha_{2} \kappa}{\left(1-p-\varepsilon_{A}\right) A} \notin\left[\bar{\pi}^{11}, \bar{\pi}^{10}\right]$ and $\frac{c+\alpha_{3} \kappa}{\left(1-p-\varepsilon_{A}\right) A} \notin\left[\bar{\pi}^{10}, \bar{\pi}^{01}\right]$. The reason is that in the case that these conditions are not satisfied we can decompose $\left[\frac{c}{\left(1-p-\varepsilon_{A}\right) A}, \frac{c+\kappa}{\left(1-p-\varepsilon_{A}\right) A}\right]$ in regions in which tasks are alternately described with rigid and contingent clauses. That exactly is case 2 .

Case 2: there exists a set of values $\pi^{i} \in\left\{\frac{c+\alpha_{i} \kappa}{\left(1-p-\varepsilon_{A}\right) A}\right\} \cup\{\bar{\pi}\}$ with $\pi^{i} \in\left[\frac{c}{\left(1-p-\varepsilon_{A}\right) A}, \frac{c+\kappa}{\left(1-p-\varepsilon_{A}\right) A}\right]$ such that all tasks with value $\pi_{n} \in\left[\min \left\{\pi^{i}\right\}, c / p A\right]$ are described with rigid clauses, all tasks with value $\pi_{n} \geq \max \left\{\pi^{i}\right\}$ are described with contingent clauses and all tasks with value $\pi_{n} \in$ $\left[\min \left\{\pi^{i}\right\}, \max \left\{\pi^{i}\right\}\right]$ are alternatively described with rigid and contingent clauses as it is shown in figure 3

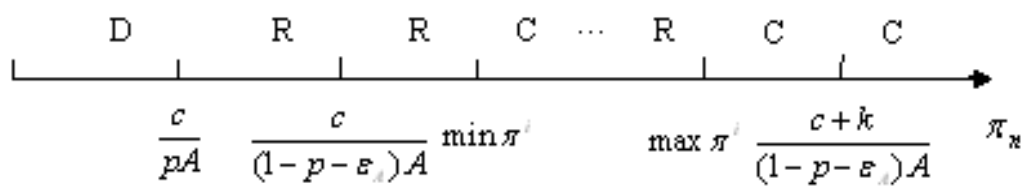

Figure 3

Optimal combination of clauses with writing and enfor cem ent costs: Case 2

The proof ends by noticing that in both cases, the most important tasks are described with contingent clauses 


\section{Vague Clauses and Optimal Contracts}

One of the most serious omissions in the framework of BM is that it does not allow the parties to include vague clauses in the contract. Vague clauses are terms which don't explicitly specify the action that the agent has to execute but instead only demand the best effort in the performed action. Examples of vague terms are: "make a decision in the best interest of the principal", "act in good faith" or "make a reasonable decision". These clauses are not only commonplace in private contracts but also in the law. An illustration is $\S 271$ of the Delaware's Corporate Law referring to the sale, lease or exchange of assets (italics are ours)

"Every corporation may at any meeting of its board of directors or governing body sell, lease or exchange all or substantially all of its property and assets, including its goodwill and its corporate franchises, upon such terms and conditions and for such consideration, which may consist in whole or in part of money or other property, including shares of stock in, and/or other securities of, any other corporation or corporations, as its board of directors or governing body deems expedient and for the best interests of the corporation"

The parties are interested in including these clauses in their contracts because, comparatively to contingent clauses, are cheaper to write. The literature argues that their main disadvantage is that they increase the enforcement costs because they generate disputes of interpretation (what the agent was supposed to execute according to the contract) more frequently. Here we show that it is not necessarily the case that vague clauses generate more trials than precise clauses. Indeed vague clauses always generate less legal disputes than contingent clauses when they are used to describe the most important tasks of the contract.

In order to understand why is that the case we have to notice that while a contingent clause demands that the agent has to perform the optimal action for the true state of nature a vague clause demands that the agent has to perform the optimal action for her believed state of nature. A direct consequence is that the probability that a precise clause generates a trial depends on the difference of beliefs between the parties about the true state of nature but the probability that a vague clause generates a trial depends on the principal's belief that the agent didn't perform the optimal action (or didn't make enough effort) for her belief about nature. A direct consequence is that the probability of a trial increases with the value of a task when the clause is contingent because a smaller conflict of beliefs between the parties is enough to trigger a trial but this probability decreases when the clause is vague because the agent performs the optimal action more frequently in order to avoid a trial in which she could be forced to pay too high expectation damages.

We model the behavior of the court assuming that it observes the signal of the agent (and not the true state of nature) and its ability is limited (not always observe correctly.) Interestingly, neither the ability of the court nor the one of the contracting parties determine whether the contract should 
be more intensive in vague or contingent clauses.

\subsection{Adding Vague Clauses}

In order to model vague clauses we introduce a new type of action that we call first best and denote $a^{*}$. Then a vague clause is of the type $T \rightarrow a^{*}$ and reads: "for any state of nature do the best action". In extensive terms $T \rightarrow a^{*}$ is equivalent to $\left(e_{n} \longrightarrow a_{n}\right) \wedge\left(\neg e_{n} \longrightarrow \neg a_{n}\right)$ nevertheless its writing cost is only $c$. Why is not obvious from there that vague clauses always dominate contingent ones? The answer is that these clauses generate different probabilities that the court decides in favor of the principal in the case of a dispute.

As already mentioned, the objective of a court that has to enforce a vague clause is to assure that the agent has performed the right action for her belief about the true state of nature. Accordingly, we assume that the court receives a signal $S_{C} \in\{1,0\}$ of the signal observed by the agent such that if $S_{C}=1$ the court believes that the agent observed $S_{A}=1$ and if $S_{C}=0$ the court believes that the agent observed $S_{A}=0$. In order to keep the results comparable, we assume that the court observes the true signal with the same probability that it observes the true state $1-\varepsilon_{C}$.

The remedy system and the timing of actions are as before.

\subsection{Strategies of the Players}

Before calculating the strategies of the players when they face vague clauses we have to notice that there is only a mixed strategies equilibrium. There is no pure strategies equilibrium because if the agent always make high effort the court always decide in favor of the agent and then trials never take place. But if trials don't take place the agent always make low effort and then we don't have an equilibrium (notice that the same logic doesn't work in the case of contingent clauses because even when there are tasks that never generate a trial the strategy of the court is not to decide in favor of the agent with certainty. The last point generates a difference in the transfer obtained by the agent when she makes high instead of low effort. That difference convinces her to make the extra effort).

\section{Court assigns responsibilities}

The court decides in favor of the agent when

Vague Clauses: the agent executed $a_{n}$ and $S_{C}=1$ or the agent executed $\neg a_{n}$ and $S_{C}=0$.

This time the a-priori probability that the court decides in favor of the agent when the clause is vague is $P\left(S_{A}=1 \mid \Omega\right)\left(1-\varepsilon_{C}\right)+P\left(S_{A}=0 \mid \Omega\right) \varepsilon_{C}$ when the agent executes $a_{n}$ and $P\left(S_{A}=1 \mid\right.$ $\Omega) \varepsilon_{C}+P\left(S_{A}=0 \mid \Omega\right)\left(1-\varepsilon_{C}\right)$ when the agent executes $\neg a_{n}$.

Principal decides to pay $t$ or sue 
In the case of vague clauses, the principal must be indifferent between suing and not suing

$$
\sigma\left(\Omega_{P}\right)\left(p\left(\Omega_{P}\right) \pi_{n}-t^{*}\right)+\left(1-\sigma\left(\Omega_{P}\right)\right)\left(\pi_{n}+p\left(\Omega_{P}\right) \pi_{n}\right)-\frac{\kappa}{2}=p\left(\Omega_{P}\right) \pi_{n}-\sigma\left(\Omega_{P}\right) t^{*}
$$

Then, independent whether the agent executed $a_{n}$ or $\neg a_{n}$ or the principal observed $e_{n}$ or $\neg e_{n}$ the court decides in favor of the agent with probability

$$
\sigma\left(\Omega_{P}\right)=1-\frac{\kappa / 2}{\pi_{n}}
$$

The probability that the court decides in favor of the agent increases with $\pi_{n}$ otherwise the principal would always prefer to sue as it becomes a dominant strategy. For the same reason the probability that the court decides in favor of the agent decreases with $\kappa$.

But the court decides in favor of the principal only when it believes that the agent performed the wrong action for her perceived signal. That is $\sigma\left(\Omega_{P}\right)$ is a function of the signal of the court and the equilibrium strategy of the agent. Then, expression (6) allows us to determine the probabilities that the agent makes high effort when she receives signal $S_{A}=1$ which we denote $\mu$ and when she receives signal $S_{A}=0$ which we denote $\bar{\mu}$. The next lemma, which we prove in the appendix, states the important result that these two expressions are increasing functions in $\pi_{n}$

Lemma 3 When the agent receives signal $S_{A}=1$ she makes high effort with probability

$$
\mu=\frac{B^{2}-A B}{B^{2}-1}
$$

when the agent receives signal $S_{A}=1$ she makes high effort with probability

$$
\bar{\mu}=\frac{B^{2}-B / A}{B^{2}-1}
$$

with $B=\frac{1-\varepsilon_{C}-\frac{\kappa}{2 \pi_{n}}}{\frac{\kappa}{2 \pi_{n}}-\varepsilon_{C}}$ and $A=\frac{\left[p\left(1-\varepsilon_{A}\right)+(1-p) \varepsilon_{A}\right]}{\left[p \varepsilon_{A}+(1-p)\left(1-\varepsilon_{A}\right)\right]}$. In addition $\mu$ and $\bar{\mu}$ are increasing in $\pi_{n}$.

The effort made by the agent increases with the value of the task because the agent is interested in avoiding a trial in which she would have to pay expectation damages are too high. In the same token, the effort made by the agent decreases with the cost of litigation because the probability that the principal sues decreases.

\section{Agent decides effort}

In a mixed strategies equilibrium the agent is indifferent between high and low effort. When 
she observes $S_{A}=1$ that is equivalent to

$$
\begin{gathered}
p_{T}\left[\left(1-\varepsilon_{C}\right) t^{*}-\varepsilon_{C} \pi_{n}-\frac{\kappa}{2}\right]-\left(1-p_{T}\right)\left[\left(1-\varepsilon_{C}\right) t^{*}\right]-\delta \pi_{n}= \\
\bar{p}_{T}\left[\varepsilon_{C} t^{*}-\left(1-\varepsilon_{C}\right) \pi_{n}-\frac{\kappa}{2}\right]-\left(1-\bar{p}_{T}\right)\left[\varepsilon_{C} t^{*}\right]
\end{gathered}
$$

where $p_{T}$ is the probability that the principal sues when he observes action $a_{n}$ and $\bar{p}_{T}$ the probability when he observes action $\neg a_{n}$. When she observes $S_{A}=0$ that is equivalent to

$$
\begin{gathered}
\bar{p}_{T}\left[\left(1-\varepsilon_{C}\right) t^{*}-\varepsilon_{C} \pi_{n}-\frac{\kappa}{2}\right]-\left(1-\bar{p}_{T}\right)\left[\left(1-\varepsilon_{C}\right) t^{*}\right]-\delta \pi_{n}= \\
p_{T}\left[\varepsilon_{C} t^{*}-\left(1-\varepsilon_{C}\right) \pi_{n}-\frac{\kappa}{2}\right]-\left(1-p_{T}\right)\left[\varepsilon_{C} t^{*}\right]
\end{gathered}
$$

From where we have that

$$
p_{T}=\bar{p}_{T}=\frac{\delta \pi_{n}+t^{*}\left(1-2 \varepsilon_{C}\right)}{\left(\pi_{n}+2 t^{*}\right)\left(1-2 \varepsilon_{C}\right)}
$$

It is direct to see that the probability that the principal initiates a trial does not depend on its own signal because that probability does not depend on the signal of the agent either (it only depends on the action). ${ }^{19}$ Does this probability increase with the value of the task? The following lemma provides us the answer

Lemma 4 Under vague clauses the frequency of trials decreases with $\pi_{n}$

Proof. It is enough to derivate (11) with respect to $\pi_{n}$

$$
\frac{\partial p_{T}}{\partial \pi_{n}}=\frac{t^{*}\left[\delta-\frac{\left(1-2 \varepsilon_{C}\right)}{2}\right]}{\left(\pi_{n}+t^{*}\right)^{2}\left(1-2 \varepsilon_{C}\right)}<0
$$

\footnotetext{
${ }^{19}$ It is true that

$p_{T}=p_{T}\left(\cdot \mid a_{n}, S_{p}=1\right) P\left(S_{p}=1 \mid S_{A}=1\right)+p_{T}\left(\cdot \mid a_{n}, S_{p}=0\right) P\left(S_{p}=0 \mid S_{A}=1\right)$$$
p_{T}=p_{T}\left(\cdot \mid a_{n}, S_{p}=1\right) P\left(S_{p}=1 \mid S_{A}=0\right)+p_{T}\left(\cdot \mid a_{n}, S_{p}=0\right) P\left(S_{p}=0 \mid S_{A}=0\right)
$$

and that

$$
\left[P\left(S_{p}=1 \mid S_{A}=1\right)-P\left(S_{p}=1 \mid S_{A}=0\right)\right]=\left[P\left(S_{p}=0 \mid S_{A}=0\right)-P\left(S_{p}=0 \mid S_{A}=1\right)\right]
$$

which implies that

Analogously we can show that

$$
p_{T}=p_{T}\left(\cdot \mid a_{n}, S_{p}=1\right)=p_{T}\left(\cdot \mid a_{n}, S_{p}=0\right)
$$

$$
\bar{p}_{T}=\bar{p}_{T}\left(\cdot \mid a_{n}, S_{p}=1\right)=\bar{p}_{T}\left(\cdot \mid a_{n}, S_{p}=0\right)
$$
}


where $\delta<\frac{\left(1-2 \varepsilon_{C}\right)}{2}$ follows from assumptions 1 and $2\left(\delta\right.$ and $\varepsilon_{C}$ are small enough)

The result is the opposite of lemma 1. The higher the value of the task that is described by the contract the smaller is the probability that the principal sues the agent. As explained before the higher is $\pi_{n}$ the more likely is that the agent will make high effort (as expectation damages of $\pi_{n}$ dominate the effort cost of $\delta \pi_{n}$ ) and with that lower the probability that the court decides in favor of the principal in the case of a legal dispute.

\subsection{Optimal Contract (with vague clauses)}

At this point we are almost ready to characterize the optimal contract when the parties have the option to write vague clauses and then compare it with the contract in which they don't have this option (the one that we characterized in Section 2.4). We just need to calculate the pay-off associated to vague clauses.

\section{Pay-off of Vague Clauses}

As in the case of contingent clauses we evaluate (5). The result, which is presented in table 4 and formally derived in the appendix tells us that the marginal benefit of the clause is equal to the probability that the agent performs the right action for a given state of nature. And that is the addition of the probability that the agent observes the true state and makes high effort (probability $\left.\left(1-\varepsilon_{A}\right) \mu\right)$ with the probability that she observes the wrong state and makes low effort (probability $\left.\varepsilon_{A}(1-\bar{\mu})\right)$.

On the side of the costs, the clause involves writing costs $c$ (only uses a primitive sentence) and enforcement costs $p_{T} \kappa$ (trials take place with probability $p_{T}$ )

\begin{tabular}{|c|c|c|}
\hline \multicolumn{3}{|c|}{ Table 4. Pay-off of Vague Clauses for Task $n$} \\
\hline Clause & Symbology & Pay-off \\
\hline Vague $(\mathrm{C})$ & $T \longrightarrow a^{*}$ & {$\left[\left(1-\varepsilon_{A}\right) \mu+\varepsilon_{A}(1-\bar{\mu})\right] A \pi_{n}-c-p_{T} \kappa$} \\
\hline
\end{tabular}

Lemmas 3 and 4 imply that the pay-off of a vague clause increases with $\pi_{n}$ and converges to $\left(1-\varepsilon_{A}\right) A \pi_{n}-c-\frac{\delta}{1-2 \varepsilon_{C}} \kappa$ form where it is direct that there exists a certain threshold for the value of the task such that all tasks which value is higher than this threshold will be described with vague and not contingent clauses. In other words, the most important tasks of the contract will be described with vague terms. That result is formally stated in the following proposition

Proposition 5 Contracts in which the parties have the option to write vague clauses are less intensive in the use of contingent clauses than contracts in which the parties don't have the option to write vague clauses. In addition, vague clauses are used to describe the most important tasks.

Proof. First we identify the values of a task that make the parties indifferent between the clauses 
that they include in their contract

$$
\left[\left(1-\varepsilon_{A}\right) \mu\left(\widehat{\pi}_{R}\right)+\varepsilon_{A}\left(1-\bar{\mu}\left(\widehat{\pi}_{R}\right)\right)-p\right] A \widehat{\pi}_{R}=p_{T}\left(\widehat{\pi}_{R}\right) \kappa
$$

and

$$
\left[\left(1-\varepsilon_{A}\right)\left(\mu\left(\widehat{\pi}_{\alpha_{i}}\right)-1\right)+\varepsilon_{A}\left(1-\bar{\mu}\left(\widehat{\pi}_{\alpha_{i}}\right)\right)\right] A \widehat{\pi}_{\alpha_{i}}=\left(p_{T}\left(\widehat{\pi}_{\alpha_{i}}\right)-\alpha_{i}\right) \kappa-c, \forall \alpha_{i} \in\left\{1, \alpha_{1}, \alpha_{2}, \alpha_{3}, 0\right\}
$$

where $\widehat{\pi}_{R}$ establishes indifference between rigid and vague and not contingent clauses. In other words, the most important tasks of the contract should be described with vague terms. That result is formally stated in the following proposition

Proposition 6 Contracts in which the parties have the option to write vague clauses are less intensive in the use of contingent clauses than contracts in which the parties don't have the option to write vague clauses. In addition, vague clauses are used to describe the most important tasks.

Proof. First we identify the values of a task that make the parties indifferent between the clauses that they include in their contract

$$
\left[\left(1-\varepsilon_{A}\right) \mu\left(\widehat{\pi}_{R}\right)+\varepsilon_{A}\left(1-\bar{\mu}\left(\widehat{\pi}_{R}\right)\right)-p\right] A \widehat{\pi}_{R}=p_{T}\left(\widehat{\pi}_{R}\right) \kappa
$$

and

$$
\left[\left(1-\varepsilon_{A}\right)\left(\mu\left(\widehat{\pi}_{\alpha_{i}}\right)-1\right)+\varepsilon_{A}\left(1-\bar{\mu}\left(\widehat{\pi}_{\alpha_{i}}\right)\right)\right] A \widehat{\pi}_{\alpha_{i}}=\left(p_{T}\left(\widehat{\pi}_{\alpha_{i}}\right)-\alpha_{i}\right) \kappa-c, \forall \alpha_{i} \in\left\{1, \alpha_{1}, \alpha_{2}, \alpha_{3}, 0\right\}
$$

where $\widehat{\pi}_{R}$ establishes indifference between rigid and vague while $\widehat{\pi}_{\alpha_{i}}$ establish indifference between contingent and vague. Depending on the order relation of theses parameters we identify three cases of optimal combination of clauses

Case 1: When $\widehat{\pi}=\min \left\{\widehat{\pi}_{R},\left\{\widehat{\pi}_{\alpha_{i}}\right\}_{i}\right\}=\widehat{\pi}_{R}$ then the optimal distribution of clauses is given by

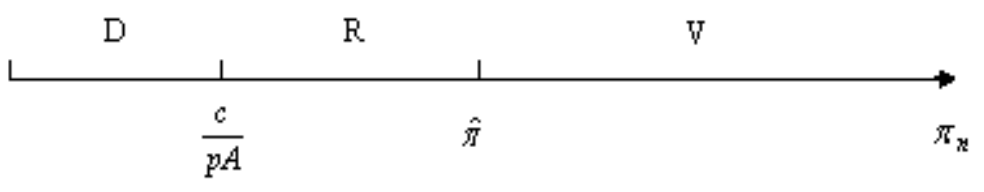

Figure 4

Optimal combination of precise and vague clauses: Case 1 
Case 2: When $\widehat{\pi}=\min \left\{\widehat{\pi}_{R},\left\{\widehat{\pi}_{\alpha_{i}}\right\}_{i}\right\} \neq \widehat{\pi}_{R}$ and we are in case 1 of proposition 2 then the optimal distribution of clauses is given by

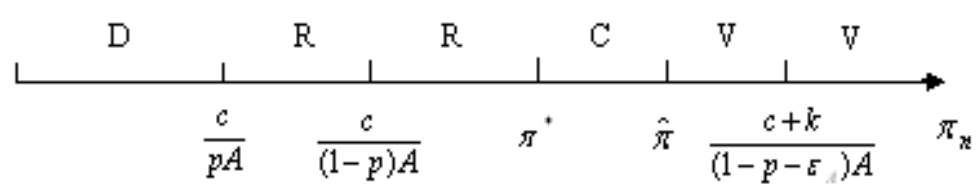

Figure 5

Optimal combination of precise and vague clauses: Case 2

Case 3: When $\widehat{\pi}=\min \left\{\widehat{\pi}_{R},\left\{\widehat{\pi}_{\alpha_{i}}\right\}_{i}\right\} \neq \widehat{\pi}_{R}$ and we are in case 2 of proposition 2 then the optimal distribution of clauses is given by

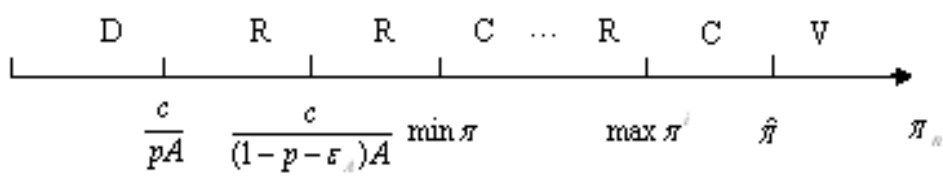

Figure 6

Optimal combination of precise and vague clauses: Case 3

In all of the cases, contingent clauses are used less than in contracts in which vague clauses are not an option and vague clauses are used to describe the most important tasks

Interestingly the result stated in proposition 5 doesn't depend on the relative abilities of the players ${ }^{20}$ which will be a prediction of Scott and Triantis. The superiority of vague clauses over contingent clauses derives from the fact that the principal sues the agent less frequently and that does not happens because the agent or the court are more or less reliable but because vague clauses

\footnotetext{
${ }^{20}$ In order to see that point more clearly we can write down the pay-off of the clauses when the solution is symmetric $p=1 / 2$ and $\pi_{n}$ is much bigger than $t^{*}$. In that case we have that $\mu=\bar{\mu}=\left(\frac{1-\varepsilon_{C}-\kappa / 2 \pi_{n}}{1-2 \varepsilon_{C}}\right)$ and the probability of a trial is $\frac{\delta}{1-2 \varepsilon_{C}}$. Then the pay-off of a vague clause becomes

$$
\left[\left(1-\varepsilon_{A}\right) \mu+\varepsilon_{A}(1-\mu)\right] A \pi_{n}-c-\frac{\delta}{1-2 \varepsilon_{C}} \kappa
$$
}

which can be rewriten as

$$
\left(\frac{1-\varepsilon_{C}-\varepsilon_{A}}{1-2 \varepsilon_{C}}\right) A \pi_{n}-c-\left(\frac{\left(\frac{1-2 \varepsilon_{A}}{2}\right) A+\delta}{1-2 \varepsilon_{C}}\right) \kappa
$$

and that expression is bigger than $\left(1-\varepsilon_{A}\right) \pi_{n}-c-\kappa$ for all values of $\varepsilon_{C}$ and $\varepsilon_{A}$. 
reduce the source of conflicts between the parties.

\section{Conclusions}

In this paper we studied how litigation affects the optimal combination of precise and vague clauses written in contracts. We showed that an analysis based in the trade-off of writing and enforcement costs is likely to lead to a suboptimal combination of clauses.

We showed that vague clauses are not only cheaper to write but they may also be cheaper to enforce. The reason is that vague clauses tend to generate less litigation than contingent clauses.

Vague clauses generate litigation less frequently because their source of conflict tends to disappear when the value of the task that is being described increases. The reason is that the agent tends to increase her effort to perform the right action in order to reduce the possibility of a lawsuit that would oblige her to pay bigger compensatory damages. Unlike that, the source of conflict in precise clauses tend to increase with the value of the task that is being described. The reason is that a smaller discrepancy between the principal and the agent about the true state of nature will be enough to trigger a trial as the value in dispute is higher. Direct implications are that contracts should be less intensive in contingent clauses than what the study of BM has suggested and vague clauses should be used to describe the most important tasks of the contract. 


\section{References}

[1] Anderlini, Luca and L. Felli (1994) "Incomplete Written Contracts: Undescribable States of Nature", Quarterly Journal of Economics, 109 (4), pp. 1085-124.

[2] _ _ _ _ (1999). "Incomplete Contracts and Complexity Costs", Theory and Decision, 46 (1), pp. 23-50.

[3] Battigalli, P. and G. Maggi (2002) "Rigidity, Discretion and the Costs of Writing Contracts", American Economic Review, 92 (4), pp. 798-817.

[4] Bernheim, D. and M. Whinston (1998) "Incomplete Contracts and Strategic Ambiguity" American Economic Review, 88 (4) pp. 902-32.

[5] Bustos, Álvaro (2005) "A Dynamic Theory of Corporate Common Law", working paper, Princeton University.

[6] Cooter, R. and Th. Ulen (2004) Law and Economics, fourth edition, Pearson-Addison Wesley.

[7] Dewatripont, M. and E. Maskin (1995) "Contractual Contingencies and Renegotiation", RAND Journal of Economics, 26 (4), pp. 704-19.

[8] Dye, Ronald (1985) "Costly Contract Contingencies", International Economic Review, 26 (1), pp. 233-50.

[9] Kaplow, Louis (1992) "Rules versus Standards: An Economic Analysis" Duke Law Journal, 42 (3), pp. 557-629.

[10] Kraakman, R. and H. Hansmann (2004) The Anatomy of Corporate Law, Oxford University Press.

[11] Krasa S. and A. Villamil (2000) "Optimal Contracts when Enforcement is a Decision Variable" Econometrica 68 (1), pp. 119-34.

[12] Scott, R. and G. Triantis (2006) "Anticipating Litigation in Contract Design." Yale Law Journal, 115 (4), pp. 814-66.

[13] Tirole, Jean (1999) "Incomplete Contracts: Where Do We Stand?" Econometrica, 67 (4), pp. 741-81.

[14] Triantis, G. (2002) "The Efficiency of Vague Contract Terms" UVA Law and Economics Research Paper No. 02-7.

\section{A Appendix}

Lemma A.1 The probability that the court decides in favor of the agent

(i) always decrease with $\varepsilon_{A}$

(ii) increases with $\varepsilon_{P}$ if and only if $S_{A}=S_{P}$

(iii.1) decreases with $\varepsilon_{C}$ if $S_{A}=S_{P}=1$

(iii.2) decreases with $\varepsilon_{C}$ if $S_{A}=S_{P}=0$ and $p<\left(1-\varepsilon_{A}\right)\left(1-\varepsilon_{P}\right) /\left(\left(1-\varepsilon_{A}\right)\left(1-\varepsilon_{P}\right)+\varepsilon_{A} \varepsilon_{P}\right)$

(iii.3) decreases with $\varepsilon_{C}$ if $S_{A}=0, S_{P}=1$ and $p<\left(1-\varepsilon_{A}\right) \varepsilon_{P} /\left(\left(1-\varepsilon_{A}\right) \varepsilon_{P}+\varepsilon_{A}\left(1-\varepsilon_{P}\right)\right)$

(iii.4) decreases with $\varepsilon_{C}$ if $S_{A}=1, S_{P}=0$ and $p>\left(1-\varepsilon_{P}\right) \varepsilon_{A} /\left(\left(1-\varepsilon_{A}\right) \varepsilon_{P}+\varepsilon_{A}\left(1-\varepsilon_{P}\right)\right)$

Proof. We derive the expressions that determine the sign of the derivative of $\sigma\left(\Omega_{P}\right)$ with respect to $\varepsilon$

Ability of the court $\left(\varepsilon_{C}\right)$

$$
\begin{gathered}
\operatorname{sgn}\left(\frac{\partial \sigma\left(\Omega_{P}^{11}\right)}{\partial \varepsilon_{C}}\right)=\operatorname{sgn}\left(\varepsilon_{A} \varepsilon_{P}(1-p)-\left(1-\varepsilon_{A}\right)\left(1-\varepsilon_{P}\right) p\right)<0 \\
\operatorname{sgn}\left(\frac{\partial \sigma\left(\Omega_{P}^{01}\right)}{\partial \varepsilon_{C}}\right)=\operatorname{sgn}\left(\varepsilon_{A}\left(1-\varepsilon_{P}\right) p-\left(1-\varepsilon_{A}\right) \varepsilon_{P}(1-p)\right) \\
\Longrightarrow \operatorname{sgn}\left(\frac{\partial \sigma\left(\Omega_{P}^{01}\right)}{\partial \varepsilon_{C}}\right)<0 \Longleftrightarrow p<\frac{\left(1-\varepsilon_{A}\right) \varepsilon_{P}}{\left(1-\varepsilon_{A}\right) \varepsilon_{P}+\varepsilon_{A}\left(1-\varepsilon_{P}\right)}
\end{gathered}
$$




$$
\begin{gathered}
\operatorname{sgn}\left(\frac{\partial \sigma\left(\Omega_{P}^{10}\right)}{\partial \varepsilon_{C}}\right)=\operatorname{sgn}\left(\varepsilon_{A}\left(1-\varepsilon_{P}\right)(1-p)-\left(1-\varepsilon_{A}\right) \varepsilon_{P} p\right) \\
\Longrightarrow \operatorname{sgn}\left(\frac{\partial \sigma\left(\Omega_{P}^{10}\right)}{\partial \varepsilon_{C}}\right)<0 \Longleftrightarrow p>\frac{\left(1-\varepsilon_{P}\right) \varepsilon_{A}}{\left(1-\varepsilon_{A}\right) \varepsilon_{P}+\varepsilon_{A}\left(1-\varepsilon_{P}\right)} \\
\operatorname{sgn}\left(\frac{\partial \sigma\left(\Omega_{P}^{00}\right)}{\partial \varepsilon_{C}}\right)=\operatorname{sgn}\left(\varepsilon_{A} \varepsilon_{P} p-\left(1-\varepsilon_{A}\right)\left(1-\varepsilon_{P}\right)(1-p)\right) \\
\Longrightarrow \operatorname{sgn}\left(\frac{\partial \sigma\left(\Omega_{P}^{00}\right)}{\partial \varepsilon_{C}}\right)<0 \Longleftrightarrow p<\frac{\left(1-\varepsilon_{P}\right)\left(1-\varepsilon_{A}\right)}{\left(1-\varepsilon_{A}\right)\left(1-\varepsilon_{P}\right)+\varepsilon_{A} \varepsilon_{P}}
\end{gathered}
$$

Ability of the agent $\left(\varepsilon_{A}\right)$

$$
\begin{gathered}
\operatorname{sgn}\left(\frac{\partial \sigma\left(\Omega_{P}^{11}\right)}{\partial \varepsilon_{A}}\right)=\operatorname{sgn}\left(\left(1-\varepsilon_{P}\right) p(1-p) \varepsilon_{P}\left(1-2 \varepsilon_{C}\right)\left(2 \varepsilon_{A}-1\right)\right)<0 \\
\operatorname{sgn}\left(\frac{\partial \sigma\left(\Omega_{P}^{01}\right)}{\partial \varepsilon_{A}}\right)=\operatorname{sgn}\left(\left(1-\varepsilon_{P}\right) \varepsilon_{P}(1-p) p\left(1-2 \varepsilon_{C}\right)\left(2 \varepsilon_{A}-1\right)\right)<0 \\
\operatorname{sgn}\left(\frac{\partial \sigma\left(\Omega_{P}^{10}\right)}{\partial \varepsilon_{A}}\right)=\operatorname{sgn}\left(\left(1-\varepsilon_{P}\right) \varepsilon_{P}(1-p) p\left(1-2 \varepsilon_{C}\right)(-1)\right)<0 \\
\operatorname{sgn}\left(\frac{\partial \sigma\left(\Omega_{P}^{00}\right)}{\partial \varepsilon_{A}}\right)=\operatorname{sgn}\left(\left(1-\varepsilon_{P}\right) \varepsilon_{P}(1-p) p\left(2 \varepsilon_{C}-1\right)\left(1-2 \varepsilon_{A}\right)\right)<0
\end{gathered}
$$

Ability of the principal $\left(\varepsilon_{P}\right)$

$$
\begin{aligned}
& \operatorname{sgn}\left(\frac{\partial \sigma\left(\Omega_{P}^{11}\right)}{\partial \varepsilon_{P}}\right)=\operatorname{sgn}\left(\left(1-\varepsilon_{A}\right) p(1-p) \varepsilon_{A}\left(2 \varepsilon_{C}-1\right)\right)<0 \\
& \operatorname{sgn}\left(\frac{\partial \sigma\left(\Omega_{P}^{01}\right)}{\partial \varepsilon_{P}}\right)=\operatorname{sgn}\left(\left(1-\varepsilon_{A}\right) p(1-p) \varepsilon_{A}\left(1-2 \varepsilon_{C}\right)\right)>0 \\
& \operatorname{sgn}\left(\frac{\partial \sigma\left(\Omega_{P}^{00}\right)}{\partial \varepsilon_{P}}\right)=\operatorname{sgn}\left(\left(1-\varepsilon_{A}\right) p(1-p) \varepsilon_{A}\left(2 \varepsilon_{C}-1\right)\right)<0 \\
& \operatorname{sgn}\left(\frac{\partial \sigma\left(\Omega_{P}^{10}\right)}{\partial \varepsilon_{P}}\right)=\operatorname{sgn}\left(\left(1-\varepsilon_{A}\right) p(1-p) \varepsilon_{A}\left(1-2 \varepsilon_{C}\right)\right)>0
\end{aligned}
$$

which ends the proof

\section{The Agent always prefer to litigate}

The agent who doesn't perform the right action and is sued wants to litigate only when

$$
-\left(1-\sigma\left(\Omega_{A}\right)\right) \pi_{n}+\sigma\left(\Omega_{A}\right) t-\kappa / 2>-\pi_{n}
$$

which is equivalent to

$$
\pi_{n}>\frac{\kappa / 2}{\sigma\left(\Omega_{A}\right)}-t
$$

Recall that the principal wants to litigate only when

$$
\pi_{n}>\frac{\kappa / 2}{1-\sigma\left(\Omega_{P}\right)}
$$

and the parties prefer litigation to settlement when

$$
-\left(1-\sigma\left(\Omega_{A}\right)\right) \pi_{n}+\sigma\left(\Omega_{A}\right) t>\left(1-\sigma\left(\Omega_{P}\right)\right) \pi_{n}-\sigma\left(\Omega_{P}\right) t
$$

As the last relation is always true $\left(\pi_{n}+t>0\right)$ we only have to analyze for each combination of signals whether (A1) implies (A0). We analyze separately the cases in which the principal and the agent observe a different signal from the cases in which they observe the same signal.

When $S_{A} \neq S_{P}$ we have that $1-\sigma\left(\Omega_{P}\right)<\sigma\left(\Omega_{A}\right)$ because the agent believes that the court decides in his favor with probability $P\left(S_{A} \neq S_{P} \mid S_{A}\right) \sigma\left(\Omega_{P}^{S_{A} \neq S_{P}}\right)+P\left(S_{A}=S_{P} \mid S_{A}\right) \sigma\left(\Omega_{P}^{S_{A}=S_{P}}\right)$ while the principal believes that the 
court decides in favor of the agent with probability $\sigma\left(\Omega_{P}^{S_{A} \neq S_{P}}\right)$ which is smaller.

When $S_{A}=S_{P}$ we have that $1-\sigma\left(\Omega_{P}\right)<\sigma\left(\Omega_{A}\right)$ because of assumption $2(\delta$ is small). For (A1) to imply (A0) it must be true that

$$
t>\frac{\kappa / 2\left(1-\sigma\left(\Omega_{P}\right)-\sigma\left(\Omega_{A}\right)\right)}{\left(1-\sigma\left(\Omega_{P}\right)\right) \sigma\left(\Omega_{A}\right)}
$$

And if we replace $t$ for $t^{*}$ the expression becomes

or

$$
\frac{\kappa / 2 \delta}{\left(1-\sigma\left(\Omega_{P}\right)\right)\left(1-\sigma\left(\Omega_{P}\right)-\sigma\left(\Omega_{A}\right)\right)}>\frac{\kappa / 2\left(1-\sigma\left(\Omega_{P}\right)-\sigma\left(\Omega_{A}\right)\right)}{\left(1-\sigma\left(\Omega_{P}\right)\right) \sigma\left(\Omega_{A}\right)}
$$

and that is true because of assumption 2 .

$$
\delta<\frac{\sigma\left(\Omega_{A}\right)}{\left(1-\sigma\left(\Omega_{P}\right)-\sigma\left(\Omega_{A}\right)\right)^{2}}
$$

\section{Value of the Transfer}

We can rewrite (3) as

$$
t>\frac{p \delta \pi_{n}+\kappa / 2\left[p_{T}\left(\Omega_{A}^{1}\right)-p_{T}\left(\bar{\Omega}_{A}^{1}\right)\right]+\pi_{n}\left[p_{T}\left(\Omega_{A}^{1}\right)\left(1-\sigma\left(\Omega_{A}^{1}\right)\right)-p_{T}\left(\bar{\Omega}_{A}^{1}\right)\left(1-\sigma\left(\bar{\Omega}_{A}^{1}\right)\right)\right]}{\sigma\left(\Omega_{A}^{1}\right)-\sigma\left(\bar{\Omega}_{A}^{1}\right)}
$$

and (4) as

$$
t>\frac{(1-p) \delta \pi_{n}+\kappa / 2\left[p_{T}\left(\bar{\Omega}_{A}^{0}\right)-p_{T}\left(\Omega_{A}^{0}\right)\right]+\pi_{n}\left[p_{T}\left(\bar{\Omega}_{A}^{0}\right)\left(1-\sigma\left(\bar{\Omega}_{A}^{0}\right)\right)-p_{T}\left(\Omega_{A}^{0}\right)\left(1-\sigma\left(\Omega_{A}^{0}\right)\right)\right]}{\sigma\left(\bar{\Omega}_{A}^{0}\right)-\sigma\left(\Omega_{A}^{0}\right)}
$$

Notice that $p_{T}\left(\bar{\Omega}_{A}^{1}\right)>p_{T}\left(\Omega_{A}^{1}\right)$ because it is more likely that the principal sues the agent when he observes $\neg a_{n}$ instead of $a_{n}$ and $\sigma\left(\Omega_{A}^{1}\right)>\sigma\left(\bar{\Omega}_{A}^{1}\right)$ because the court is more likely to decide for the agent when she executes $a_{n}$ than when she executes $\neg a_{n}$. In the same way $p_{T}\left(\Omega_{A}^{0}\right)>p_{T}\left(\bar{\Omega}_{A}^{0}\right)$ and $\sigma\left(\bar{\Omega}_{A}^{0}\right)>\sigma\left(\Omega_{A}^{0}\right)$. Then it is direct that the right hand side of (A2) is maximum when $p_{T}\left(\Omega_{A}^{1}\right)=p_{T}\left(\bar{\Omega}_{A}^{1}\right)=0$ and the right hand side of (A3) is maximum when $p_{T}\left(\Omega_{A}^{0}\right)=p_{T}\left(\bar{\Omega}_{A}^{0}\right)=0$. Then, if we impose that the transfer is $t^{*}$ we have that (A2) and (A3) are always satisfied.

\section{Coefficients in Table 3}

As neither rigid nor discretionary clauses generate trials, they have no enforcement costs associated. In the case of contingent clauses we identify the values of $\widetilde{E}_{S}^{i j}$ and $\bar{E}_{S}^{i j}$ as follows

\begin{tabular}{|c|c|c|c|}
\hline \multicolumn{4}{|c|}{ Values of $\widetilde{E}_{S}^{i j}$ (there is litigation) } \\
\hline & Principal & Agent & Aggregate \\
\hline$\widetilde{E}_{S}^{11}=\widetilde{E}_{S}^{10}$ & $\pi_{n}-\left(1-\varepsilon_{C}\right) t^{*}+\varepsilon_{C} \pi_{n}-\kappa / 2$ & $\left(1-\varepsilon_{C}\right) t^{*}-\varepsilon_{C} \pi_{n}-\kappa / 2-\delta \pi_{n}$ & $A \pi_{n}-\kappa$ \\
\hline$\widetilde{E}_{S}^{01}=\widetilde{E}_{S}^{00}$ & $-\left(1-\varepsilon_{C}\right) t^{*}+\varepsilon_{C} \pi_{n}-\kappa / 2$ & $\left(1-\varepsilon_{C}\right) t^{*}-\varepsilon_{C} \pi_{n}-\kappa / 2-\delta \pi_{n}$ & $-\kappa$ \\
\hline
\end{tabular}

\begin{tabular}{|l|c|c|c|}
\hline \multicolumn{4}{|c|}{ Values of $\bar{E}_{S}^{i j}$ (there is no litigation) } \\
\hline & Principal & Agent & Aggregate \\
\hline $\bar{E}_{S}^{11}=\bar{E}_{S}^{10}$ & $\pi_{n}-t^{*}$ & $t^{*}-\delta \pi_{n}$ & $A \pi_{n}$ \\
\hline $\bar{E}_{S}^{01}=\bar{E}_{S}^{00}$ & $-t^{*}$ & $t^{*}$ & 0 \\
\hline
\end{tabular}

Then we calculate the pay-off $(P O)$ of the contingent clause for all values of $\pi_{n}$

1. For $\pi_{n}>\bar{\pi}^{11}$ there is always litigation

$$
P O=p\left\{\left(1-\varepsilon_{A}\right) \widetilde{E}_{S}^{11}+\varepsilon_{A} \widetilde{E}_{S}^{01}\right\}+(1-p)\left\{\left(1-\varepsilon_{A}\right) \widetilde{E}_{S}^{10}+\varepsilon_{A} \widetilde{E}_{S}^{00}\right\}-2 c
$$




$$
P O=\left(1-\varepsilon_{A}\right) A \pi_{n}-\kappa-2 c
$$

2. For $\pi_{n} \in\left[\bar{\pi}^{00}, \bar{\pi}^{11}\right]$ there is always litigation unless $S_{A}=S_{P}=1$

$$
\begin{gathered}
P O=p\left\{\left(1-\varepsilon_{A}\right)\left[\left(1-\varepsilon_{P}\right) \bar{E}_{S}^{11}+\varepsilon_{P} \widetilde{E}_{S}^{10}\right]+\varepsilon_{A} \widetilde{E}_{S}^{01}\right\}+(1-p)\left\{\left(1-\varepsilon_{A}\right) \widetilde{E}_{S}^{00}+\varepsilon_{A}\left[\left(1-\varepsilon_{P}\right) \widetilde{E}_{S}^{10}+\varepsilon_{P} \bar{E}_{S}^{11}\right]\right\}-2 c \\
P O=\begin{array}{c}
p\left\{\left(1-\varepsilon_{A}\right)\left[\left(1-\varepsilon_{P}\right) A \pi_{n}+\varepsilon_{P}\left(A \pi_{n}-\kappa\right)\right]+\varepsilon_{A}(-\kappa)\right\}+ \\
(1-p)\left\{\left(1-\varepsilon_{A}\right)(-\kappa)+\varepsilon_{A}\left[\left(1-\varepsilon_{P}\right)\left(A \pi_{n}-\kappa\right)+\varepsilon_{P} A \pi_{n}\right]\right\}-2 c
\end{array} \\
P O=\left(1-\varepsilon_{A}\right) A \pi_{n}-\left[p\left(\left(1-\varepsilon_{A}\right) \varepsilon_{P}+\varepsilon_{A}\right)+(1-p)\left(1-\varepsilon_{A} \varepsilon_{P}\right)\right] \kappa-2 c
\end{gathered}
$$

3. For $\pi_{n} \in\left[\bar{\pi}^{10}, \bar{\pi}^{00}\right]$ there is always litigation unless $S_{A}=S_{P}=1$ and $S_{A}=S_{P}=0$

$$
\begin{aligned}
P O= & p\left\{\left(1-\varepsilon_{A}\right)\left[\left(1-\varepsilon_{P}\right) \bar{E}_{S}^{11}+\varepsilon_{P} \widetilde{E}_{S}^{10}\right]+\varepsilon_{A}\left[\left(1-\varepsilon_{P}\right) \widetilde{E}_{S}^{01}+\varepsilon_{P} \bar{E}_{S}^{00}\right]\right\}+ \\
& (1-p)\left\{\left(1-\varepsilon_{A}\right)\left[\left(1-\varepsilon_{P}\right) \bar{E}_{S}^{00}+\varepsilon_{P} \widetilde{E}_{S}^{01}\right]+\varepsilon_{A}\left[\left(1-\varepsilon_{P}\right) \widetilde{E}_{S}^{10}+\varepsilon_{P} \bar{E}_{S}^{11}\right]\right\}-2 c \\
P O= & p\left\{\left(1-\varepsilon_{A}\right)\left[\left(1-\varepsilon_{P}\right) A \pi_{n}+\varepsilon_{P}\left(A \pi_{n}-\kappa\right)\right]+\varepsilon_{A}\left[\left(1-\varepsilon_{P}\right)(-\kappa)+\varepsilon_{P} 0\right]\right\}+ \\
& (1-p)\left\{\left(1-\varepsilon_{A}\right)\left[\left(1-\varepsilon_{P}\right) 0+\varepsilon_{P}(-\kappa)\right]+\varepsilon_{A}\left[\left(1-\varepsilon_{P}\right)\left(A \pi_{n}-\kappa\right)+\varepsilon_{P} A \pi_{n}\right]\right\}-2 c \\
& P O=\left(1-\varepsilon_{A}\right) A \pi_{n}-\left[\left(1-\varepsilon_{A}\right) \varepsilon_{P}+\left(1-\varepsilon_{P}\right) \varepsilon_{A}\right] \kappa-2 c
\end{aligned}
$$

4. For $\pi_{n} \in\left[\bar{\pi}^{01}, \bar{\pi}^{10}\right]$ there is only litigation when $S_{A}=0$ and $S_{P}=1$

$$
\begin{gathered}
P O=p\left\{\left(1-\varepsilon_{A}\right) \bar{E}_{S}^{11}+\varepsilon_{A}\left[\left(1-\varepsilon_{P}\right) \widetilde{E}_{S}^{01}+\varepsilon_{P} \bar{E}_{S}^{00}\right]\right\}+(1-p)\left\{\left(1-\varepsilon_{A}\right)\left[\left(1-\varepsilon_{P}\right) \bar{E}_{S}^{00}+\varepsilon_{P} \widetilde{E}_{S}^{01}\right]+\varepsilon_{A} \bar{E}_{S}^{11}\right\}-2 c \\
P O=p\left\{\left(1-\varepsilon_{A}\right) A \pi_{n}+\varepsilon_{A}\left[\left(1-\varepsilon_{P}\right)(-\kappa)+\varepsilon_{P} 0\right]\right\}+(1-p)\left\{\left(1-\varepsilon_{A}\right)\left[\left(1-\varepsilon_{P}\right) 0+\varepsilon_{P}(-\kappa)\right]+\varepsilon_{A} A \pi_{n}\right\}-2 c \\
P O=\left(1-\varepsilon_{A}\right) A \pi_{n}-\left[(1-p)\left(1-\varepsilon_{A}\right) \varepsilon_{P}+p\left(1-\varepsilon_{P}\right) \varepsilon_{A}\right] \kappa-2 c
\end{gathered}
$$

5. For $\pi_{n}<\bar{\pi}^{01}$ there is never litigation

$$
\begin{gathered}
P O=p\left\{\left(1-\varepsilon_{A}\right) \bar{E}_{S}^{11}+\varepsilon_{A} \bar{E}_{S}^{01}\right\}+(1-p)\left\{\left(1-\varepsilon_{A}\right) \bar{E}_{S}^{10}+\varepsilon_{A} \bar{E}_{S}^{00}\right\}-2 c \\
P O=\left(1-\varepsilon_{A}\right) A \pi_{n}-2 c
\end{gathered}
$$

\section{Proof of Lemma 3}

We know that in the case that the agent executes action $a_{n}$ the court decides in her favor only when it observes $S_{C}=1$ which is equal to

$$
P\left(S_{C}=1 \mid S_{A}=1\right) P\left(S_{A}=1 \mid a_{n}\right)+P\left(S_{C}=1 \mid S_{A}=0\right) P\left(S_{A}=0 \mid a_{n}\right)=1-\frac{\kappa / 2}{\pi_{n}}
$$

analogously, in the case in which the agent executes action $\neg a_{n}$ the court decides in her favor only when it observes $S_{C}=0$ which is equal to

$$
P\left(S_{C}=0 \mid S_{A}=1\right) P\left(S_{A}=1 \mid \neg a_{n}\right)+P\left(S_{C}=0 \mid S_{A}=0\right) P\left(S_{A}=0 \mid \neg a_{n}\right)=1-\frac{\kappa / 2}{\pi_{n}}
$$

We can rewrite these identities as

$$
\frac{\left(1-\varepsilon_{C}\right) \mu\left[p\left(1-\varepsilon_{A}\right)+(1-p) \varepsilon_{A}\right]+\varepsilon_{C}(1-\bar{\mu})\left[p \varepsilon_{A}+(1-p)\left(1-\varepsilon_{A}\right)\right]}{\mu\left[p\left(1-\varepsilon_{A}\right)+(1-p) \varepsilon_{A}\right]+(1-\bar{\mu})\left[p \varepsilon_{A}+(1-p)\left(1-\varepsilon_{A}\right)\right]}=1-\frac{\kappa / 2}{\pi_{n}}
$$

and

$$
\frac{\varepsilon_{C}(1-\mu)\left[p\left(1-\varepsilon_{A}\right)+(1-p) \varepsilon_{A}\right]+\left(1-\varepsilon_{C}\right) \bar{\mu}\left[p \varepsilon_{A}+(1-p)\left(1-\varepsilon_{A}\right)\right]}{(1-\mu)\left[p\left(1-\varepsilon_{A}\right)+(1-p) \varepsilon_{A}\right]+\bar{\mu}\left[p \varepsilon_{A}+(1-p)\left(1-\varepsilon_{A}\right)\right]}=1-\frac{\kappa / 2}{\pi_{n}}
$$


which gives us (7) and (8). Next we derivate both expressions with respect to $\pi_{n}$ and obtain

which ends the proof

$$
\begin{gathered}
\frac{\partial \mu}{\partial \pi_{n}}=\frac{A\left[(B-1)^{2}+2 B(1-1 / A)\right]}{\left(B^{2}-1\right)^{2}} \frac{\partial B}{\partial \pi_{n}}>0 \\
\frac{\partial \bar{\mu}}{\partial \pi_{n}}=\frac{\left[B^{2}+1-2 B A\right]}{A\left(B^{2}-1\right)^{2}} \frac{\partial B}{\partial \pi_{n}}>0
\end{gathered}
$$

\section{Coefficients in Table 4}

In the case of vague clauses we identify the values of $\widetilde{E}_{S}^{i j}$ and $\bar{E}_{S}^{i j}$ as follows

\begin{tabular}{|c|c|c|c|}
\hline \multicolumn{4}{|c|}{ Values of $\widetilde{E}_{S}^{i j}$ (there is litigation) } \\
\hline & Principal & Agent & Aggregate \\
\hline$\widetilde{E}_{S}^{11}=\widetilde{E}_{S}^{10}$ & $2 \mu \pi_{n}-\mu t^{*}-\kappa / 2$ & $\mu t^{*}-\mu \pi_{n}(1+\delta)-\kappa / 2$ & $\mu A \pi_{n}-\kappa$ \\
\hline$\widetilde{E}_{S}^{01}=\widetilde{E}_{S}^{00}$ & $2(1-\widetilde{\mu}) \pi_{n}-(1-\widetilde{\mu}) t^{*}-\kappa / 2$ & $(1-\widetilde{\mu}) t^{*}-(1-\widetilde{\mu})(1+\delta) \pi_{n}-\kappa / 2$ & $(1-\widetilde{\mu}) A \pi_{n}-\kappa$ \\
\hline
\end{tabular}

\begin{tabular}{|l|c|c|c|}
\hline \multicolumn{4}{|c|}{ Values of $\bar{E}_{S}^{i j}$ (there is no litigation) } \\
\hline & Principal & Agent & Aggregate \\
\hline $\bar{E}_{S}^{11}=\bar{E}_{S}^{10}$ & $\mu \pi_{n}-\mu t^{*}$ & $-\mu \delta \pi_{n}+\mu t^{*}$ & $\mu A \pi_{n}$ \\
\hline $\bar{E}_{S}^{01}=\bar{E}_{S}^{00}$ & $(1-\widetilde{\mu}) \pi_{n}-\mu t^{*}$ & $-(1-\widetilde{\mu}) \delta \pi_{n}+\mu t^{*}$ & $(1-\widetilde{\mu}) A \pi_{n}$ \\
\hline
\end{tabular}

from where we retrieve the payoffs in table 4 . 